\title{
APPLICATION OF THE PRINCIPLE OF THE SEMANTIC CIRCLE AND MAIN HEURISTIC OPERATIONS IN SYNTHESIS OF NEW FORMS AND IMAGES
}

\author{
Petya Boneva, Vladimir Bonev \\ University of Ruse, Agrarian and Industrial Faculty, \\ Department of Industrial Design, \\ 8 Studentska str., POB 7017, Ruse, Bulgaria, \\ e-mail: pboneva@uni-ruse.bg
}

\begin{abstract}
The semantic circle of visual forms is a stimulating creative and innovative thinking novelty in education and practice, introducing new concepts, approaches, methods and techniques in the analysis and synthesis of visualizations, communications and presentations. Heuristic operations are techniques, prescriptions for conversion of existing situations into a new, unexpected or unusual direction, with the expectation of obtaining results unachievable along the path of formal logic, i.e. by known logical operations, judgments and inferences. This study reveals the nature, structure and application of the semantic circle in the synthesis of visual solutions, also including solving specific creative and innovative tasks that are focused in different thematic areas.
\end{abstract}

Keywords: Function, semantics and expressiveness of visual forms, Semantic circle of visual forms and images, Basic heuristic operations.

\section{INTRODUCTION}

In all spheres of human activity for which the creativity and innovation are priorities, communications and presentations are permanent objective, strategy, tools and resources created and-or use a variety of visual forms, images, pictures, compositions, etc., following two dominant trends. The first - expressiveness that „Picture is worth than a thousand words". Second, caused by aesthetics and art contained in the above-cited words of Salvador Dali $[1,6]$.

The trend of semantic circle found a surprising reception and easy comprehension and assimilation, interpretation and implementation of students and professionals in training, analysis and synthesis, including research and resolve a new class of creative and innovative tasks [1, 2, 7, 9, 10].

The Semantic circle proved not to be artistic exoticism and not suspected and serious creative and innovative instrumentation leading to definition of new creative research tasks of analysis and synthesis of visual forms, images, pictures and compositions [1].

The reality is replete with vast in quantity and quality wealth of visual solutions and creations that give rise to several questions:

$\checkmark$ How to train future artists and professionals to analyze and synthesize?;

$\checkmark$ How to contact them in three basic aesthetic categories;

$\checkmark$ Function (purpose);

$\checkmark$ Information expressiveness - the relevance of secondary - format/ structure of the primary - the function;

$\checkmark$ Semantics (meaning, significance - as the content of semantic information). 


\section{IRTITE}

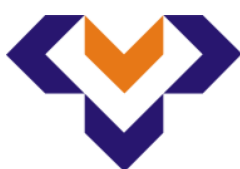

Ipplied Reseitrones in Technics, Technologies and Bductition

Journal of the Faculty of Technics and Technologies, Trakia University https:///sites.google.com/a/trakia-uni.bg/artte/

How to react to stressful situations and the real aesthetic shocks summarized in the emphases:

$\checkmark$ Why not everything is understandable visual / logical, but "skipped over" - in the transcendent "senseless" inexplicable and incompatible with the values?

$\checkmark \quad$ Why people do not like what they do not understand?

All that complicates enormously the perception and interpretation of visual and verbal categories and resources as tools of communication and presentation.

The report aims to generate images with semantic value and standard solutions for semantic circle, using basic heuristic operations.

\section{GENERATING IMAGES HAVING SEMANTIC VALUE}

The primary longing of humanity for unity in the most exquisite form - the circle and the desire to not many words to be said everything is done in the original concept of N. Orloev [8] as a natural structure in which the main concern is dedicated to that straight $\mathrm{K}, \mathrm{G} / \mathrm{C}$ and $\mathrm{A}$ forms, and bi-component forms, images and pictures according to Figure 1.

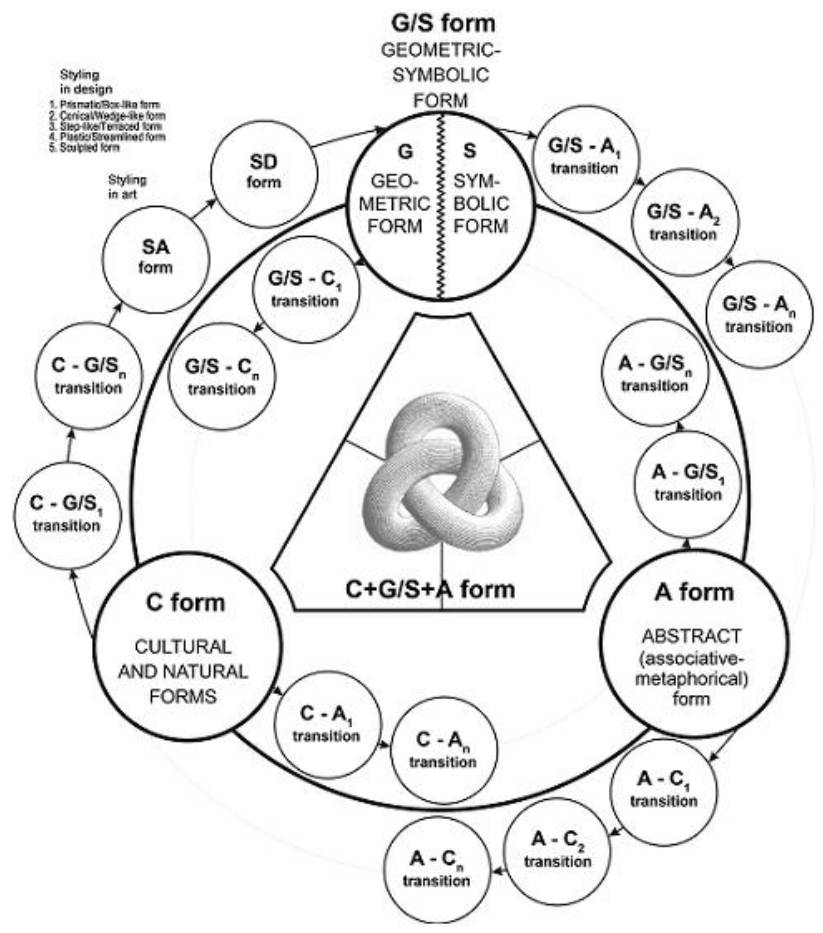

a) Conceptual model with simplified structure

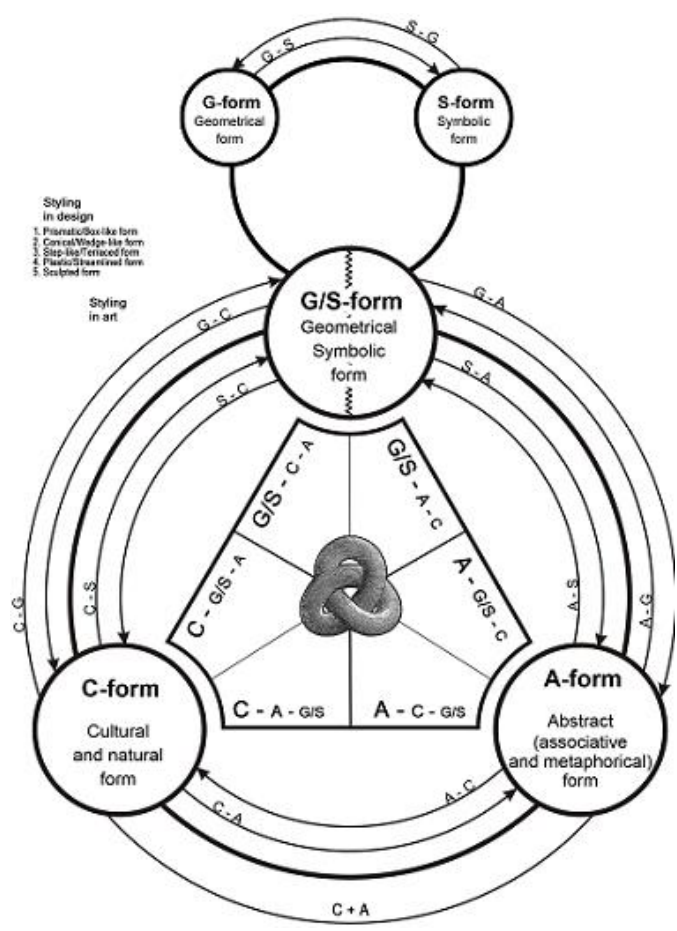

b) Conceptual model with extended structure (by N. Orloev [8])

Figure 1. Semantic circle of visual forms and images used in education

Regardless of their unevenness visual forms are implemented singly or through joint implementation of four major functional and structural semantic elements:

$\checkmark$ K-form. Cultural, natural form - a product of evolution (inanimate nature, fauna and flora), and co-evolution (products of conscious creative human activity);

$\checkmark$ A-form. Abstract, metaphorical-associative form;

IRTIIE Vol. 4, No. 2, 2016 ISSN 1314-8788 (print), ISSN 1314-8796 (online), doi: 10.15547/artte.2016.02.004 


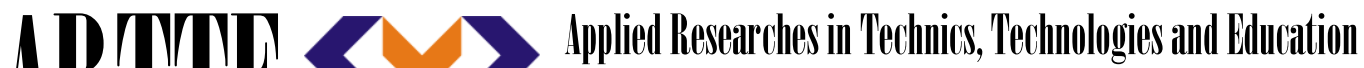 Journal of the Faculty of Technics and Technologies, Trakia University https://sites.google.com/a/trakia-uni.bg/artte/}

$\checkmark$ G/C form. Geometric / Symbol form, formally meaningful connection and two independent and interpenetrating categories.

$\checkmark$ G-shaped - objects with a clear geometric structure; product target geometric constructions;

$\checkmark$ C-shape - character (characters, letters, numbers, symbolic values analogues of spirituality).

The main heuristic operations (MHO) - applicable when certain processes or can ever be fully and clearly, unambiguously and logically described, or is only partially complete, and only with the use of multiple fuzzy and unequal recommendations and rules (heuristic techniques, approaches and programs) and funds. This type of mental operations allow reduction of the creative efforts and intellectual energy consumption $[3,4,8]$, improves the performance and efficacy are creative and search for a solution takes more targeted. However, without providing a guarantee for finding and categorizing good and subtle, strong and great decisions.

The main heuristic operations are classified into certain 'logical' or meaningful order. However, they are grouped into four arrays:

$\checkmark$ Increase, gain acceleration parameters and characteristics, quantitative and qualitative indicators;

$\checkmark$ Decrease, lowering, reducing the parameters and characteristics, quantitative and qualitative indicators;

$\checkmark$ Structure / structuring including function, organization and hierarchy of product composition objects, complex systems;

$\checkmark \quad$ Making special qualities and characteristics of forms, compositions, objects and subjects of complex systems and organizations.

It is amazing that in this seemingly unmanageable or impassable chaos the identification is possible due to the semantics specifically, the idea of semantic circle.

Any creative trend can be positioned and realized in the desired place by the author in a semantic circle, thus can give her virtually unlimited options for interpretation / improvisation.

\section{ANALYSIS AND CREATIVE-INNOVATIVE SYNTHESIS OF TYPE SOLUTIONS FOR SEMANTIC CIRCLE USING MHO}

The theory of perception, respectively, making meaning, interpretation and understanding of the visual and verbal aspects and dimensions of the outside world, enriched by material and spiritual, constructed by man confronts us with multiple extremes and phenomena $[1,2,5,6$, 8].

In the report are designed two standard solutions based on the extended structure of the Semantic circle.

The purpose is by the use of a base form (K-form) to synthesize a series of images, pictures, basic shapes and the transitions between them, using the main heuristic operations.

Figure 2 shows the development of a random form by changing its quantitative and qualitative indicators.

Figure 3 shows shapes, pictures, images, again by a series of single or multiple applied heuristic operations (methods).

Using logical-intuitive approach leads to "melting" of the base form (K-form), but retains a common theme - "Woman". 


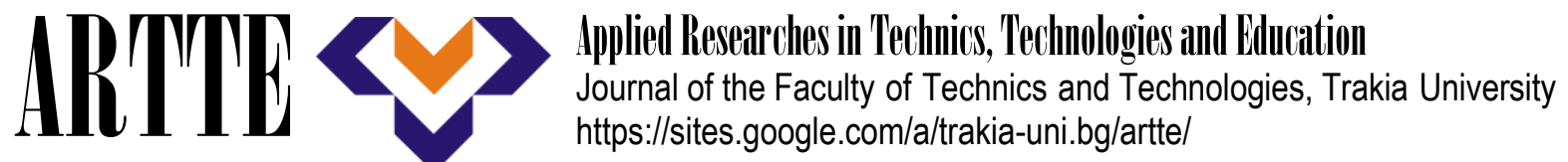

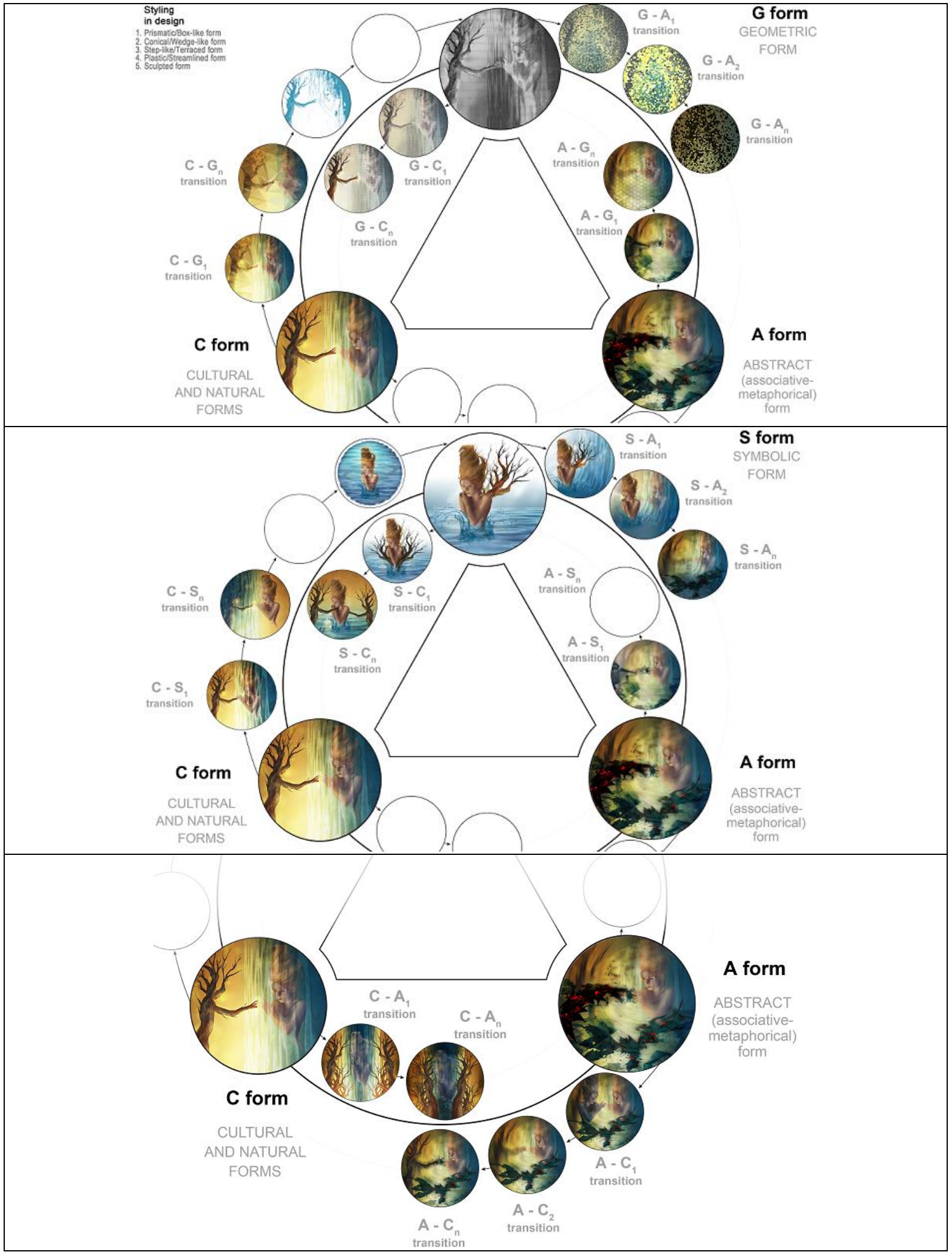

Figure 2. Semantic circle of visual shapes, images and pictures, consists of one main form (K-form) by use of $\mathrm{MHO}$

IRTIIE Vol. 4, No. 2, 2016 ISSN 1314-8788 (print), ISSN 1314-8796 (online), doi: 10.15547/artte.2016.02.004 


\section{ARTTIE}

Ipplied Researches in Technics, Technologies ind Bducition

Journal of the Faculty of Technics and Technologies, Trakia University https://sites.google.com/a/trakia-uni.bg/artte/

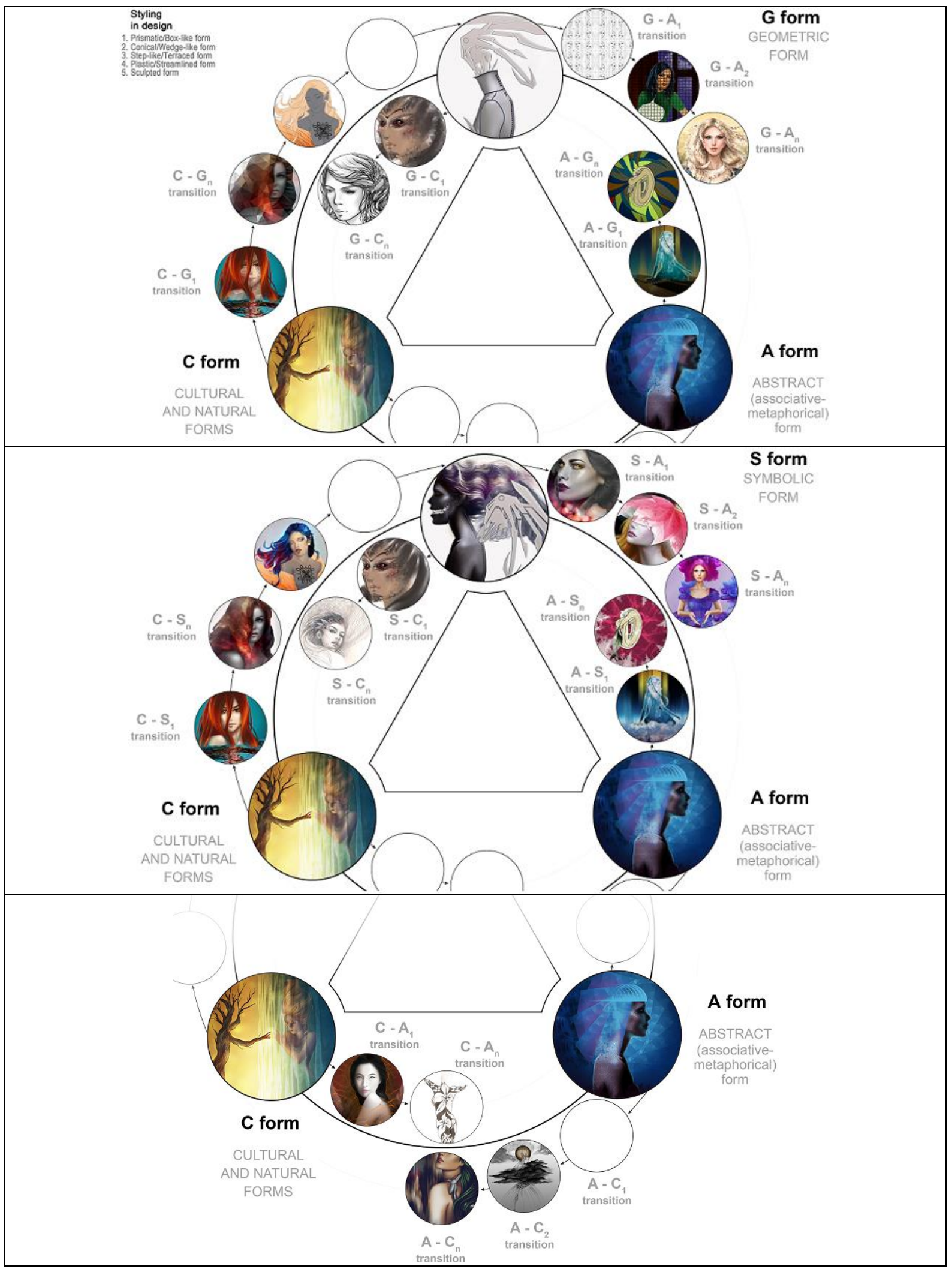

Figure 3. Semantic circle of visual forms and images by using $\mathrm{MHO}$ IRTTIE Vol. 4, No. 2, 2016 ISSN 1314-8788 (print), ISSN 1314-8796 (online), doi: 10.15547/artte.2016.02.004 


\section{IRTTL}

Ipplied Reseitrones in Technics, Technologies and Bductition

Journal of the Faculty of Technics and Technologies, Trakia University https://sites.google.com/a/trakia-uni.bg/artte/

\section{CONCLUSION}

Heuristics such as prescriptions, not only indicate logical way, i.e. what can or should be done, but they provide partial guidance on how it makes sense to do so. They can give instructions to prevent possible errors as "accumulate" experience of creative, heuristic, innovative and inventive-discovery activities.

The Semantic circle is an original hypothesis and model of heuristic classification of visual images regardless of the type and purpose. The hypothesis brings enough objectivity to make it possible to find a common point of view of a common "language" for Creation and understanding / interpretation based on projected sense significance.

The theory of perception, respectively, understanding, interpretation and interpretation of visual and verbal aspects and dimensions of the outside world, enriched by material and spiritual created by man confronts us with a number of extremes and phenomena such as:

$\checkmark$ Material and spiritual (intangible);

$\checkmark$ A circuit (solid) and not circuit (respectively, liquid, gas and diffuse);

$\checkmark$ Observable and unobservable, respectively field;

$\checkmark$ Real and abstract;

$\checkmark$ Digital and ambiguous;

$\checkmark$ Rational and irrational;

$\checkmark$ Definiteness and indefiniteness;

$\checkmark \quad$ Structured and unstructured (amorphous);

$\checkmark$ Predictable and unpredictable (random, fantastic);

$\checkmark \quad$ Linear and nonlinear; Understandable and incomprehensible;

$\checkmark$ Meaningful and meaningless;

$\checkmark \quad$ Images and concepts in language;

$\checkmark$ Low and high threshold semantic personality because of quantitative and qualitative levels of thesaurus and others.

These phenomena complicate perception, interpretation and interpretation of visual and verbal categories and approaches as tools for communicating and presenting information.

The Semantic circle is actively used in recent years in training of students from different specialties of the University of Ruse. It developed and improved cognitive and cultural horizon of personality and was met well with interest as the creative application task.

On the other hand, the Semantic circle has a high didactic potential applicable and very effective in the development and improvement of knowledge and skills in communication and presentation both in perception, construction and perception of visual and by analogy and verbal images - of words and thought, speech culture.

\section{REFERENCES}

[1] Boneva P., Orloev N., Beloev H., SEMANTIC CIRCLE - analysis and synthesis of standard solutions, Intl. Conference ICERI - Proceedings, Seville, November, 2014.

[2] Dimitrova A., Analysis of SEM images of magnetically threated ceramic materials. Applied scientific journal, Innovation and entrepreneurship, vol. 3, No.4, 2015, ISSN 1314-9253, pp.35-43.

[3] Dineva P., Design of asymmetric ladies' dresses with 3D elements, Annals of the University of Oradea, Vol. XVII, No.2, 2016, ISSN $1843-813$ X, pp.35-40.

[4] Dineva P., Design of Peplums with Different Forms in Ladies' Dresses, Proc. of the International Conference in Technics, Technologies and Education ICTTE 2014, Yambol, Bulgaria, pp.291-301.

IRTIIE Vol. 4, No. 2, 2016 ISSN 1314-8788 (print), ISSN 1314-8796 (online), doi: 10.15547/artte.2016.02.004 


\section{IRTTE

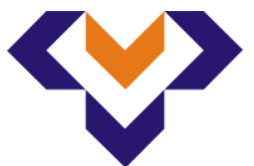 \\ Ipplied Researlohes in Technics, Technologies and Bductition \\ Journal of the Faculty of Technics and Technologies, Trakia University https:///sites.google.com/a/trakia-uni.bg/artte/}

[5] Georgiev G., N. Georgieva, Investigation possibilities for the use of free software for data processing used for accurate measurement details through photogrammetry. ARTTE Vol. 2, No. 3, 2014, ISSN 1314-8796, pp. 202-210.

[6] Kazlacheva Z., Fibonacci Rose in Fashion Design. ARTTE Applied Researches in Technics, Technologies and Education, Vol. 2, No. 3, 2014, ISSN 1314-8796, pp. 224230.

[7] Nedeva, V., Z. Zlatev, S. Atanasov, Effective Resources Use for Virtual Laboratories through Cloud Computing and Services. In ICVL, The 7th International Conference on Virtual Learning, 2012, pp.322-328.

[8] Orloev N., H. Beloev, P. Boneva, Semantic circle of visual forms/images, International Conference of Education, Research and Innovation, 17-19 November, 2014, Seville, Spain, ICERI2014 Proceedings, ISSN: 2340-1095, pp.5064-5072.

[9] Stoykova, V., Evaluation of the application of interactive presentation systems in higher education, ARTTE, Applied Researches in Technics, Technologies and Education, Journal of the Faculty of Technics and Technologies, Trakia University, Vol. 2, No. 3, 2014, ISSN 1314-8796, pp.286-300.

[10] Zlatev, Z., J. Ilieva, Design of textile patterns by using colors from the Bulgarian national costumes, ARTTE, Vol. 3, No. 4, 2015, ISSN 1314-8796, pp.309-316. 